\title{
Erratum to: Influence of Positive Surgical Margin Status After Radical Nephroureterectomy on Upper Urinary Tract Urothelial Carcinoma Survival
}

Pierre Colin, $\mathrm{MD}^{1,15}$, Adil Ouzzane, $\mathrm{MD}^{1}$, David R. Yates, $\mathrm{MD}^{2}$, François Audenet, $\mathrm{MD}^{2}$, Géraldine Pignot, $\mathrm{MD}^{3}$, Alexis Arvin-Berod, $\mathrm{MD}^{4}$, Olivier Merigot de Treigny, $\mathrm{MD}^{5}$, Guy Laurent, $\mathrm{MD}^{6}$, Antoine Valeri, $\mathrm{MD}, \mathrm{PhD}^{7}$, Jacques Irani, $\mathrm{MD}, \mathrm{PhD}^{8}$, Fabien Saint, $\mathrm{MD}$, $\mathrm{PhD}^{9}$, Solène Gardic, $\mathrm{MD}^{10}$, Pascal Gres, $\mathrm{MD}^{11}$, François Rozet, $\mathrm{MD}^{12}$, Yann Neuzillet, $\mathrm{MD}^{13}$, Alain Ruffion, $\mathrm{MD}, \mathrm{PhD}^{14}$, and Morgan Rouprêt, $\mathrm{MD}, \mathrm{PhD}^{2}$

${ }^{1}$ Academic Department of Urology, CHRU Lille, Lille Nord de France University, Lille, France; ${ }^{2}$ Academic Department of Urology of la Pitié-Salpêtrière Hospital, Assistance Publique-Hôpitaux de Paris, Faculté de Médecine Pierre et Marie Curie, University Paris VI, Paris, France; ${ }^{3}$ Academic Department of Urology, Cochin Hospital, Assistance PubliqueHôpitaux de Paris, René Descartes University, Paris, France; ${ }^{4}$ Academic Department of Urology, CHRU Grenoble, University of Grenoble, Grenoble, France; ${ }^{5}$ Academic Department of Urology, CHRU Toulouse, University of Toulouse, Toulouse, France; ${ }^{6}$ Academic Department of Urology, CHRU Clermont-Ferrand, University of Clermont-Ferrand, Clermont-Ferrand, France; ${ }^{7}$ Academic Department of Urology, CHRU Brest, University of Brest, Brest, France; ${ }^{8}$ Academic Department of Urology, CHRU Poitiers, University of Poitiers, Poitiers, France; ${ }^{9}$ Academic Department of Urology, CHRU Amiens, University of Amiens, Amiens, France; ${ }^{10}$ Academic Department of Urology, CHRU Limoges, University of Limoges, Limoges, France; ${ }^{11}$ Academic Department of Urology, CHRU Nîmes, University of Nîmes, Nîmes, France; ${ }^{12}$ Department of Urology, Institut Mutualiste Montsouris, Paris, France; ${ }^{13}$ Academic Department of Urology, Academic Hospital of Foch, Suresnes, France; ${ }^{14}$ Academic Department of Urology, CHRU Lyon Sud, University of Lyon, Lyon, France; ${ }^{15}$ Hôpital Claude Huriez, Lille, France

ERRATUM TO: ANN SURG ONCOL (2012) 19:3613-3620

DOI 10.1245/S10434-012-2453-9

In the published byline of the article entitled "Influence of Positive Surgical Margin Status After Radical Nephroureterectomy on Upper Urinary Tract Urothelial Carcinoma Survival," the first and surnames of the fourth and tenth authors were reversed. The names should read François Audenet instead of Audenet François and Jacques Irani as shown on the correct byline above.

The online version of the original article can be found under doi:10.1245/s10434-012-2453-9.

(C) Society of Surgical Oncology 2012

First Received: 19 October 2012;

Published Online: 19 November 2012

P. Colin, MD

e-mail: pierre.colin@chru-lille.fr 